\title{
Van voorproever tot toxicoloog
}

Citation for published version (APA):

Bast, A. (1999). Van voorproever tot toxicoloog. Universiteit Maastricht.

https://doi.org/10.26481/spe.19991203ab

Document status and date:

Published: 03/12/1999

DOI:

10.26481/spe.19991203ab

Document Version:

Publisher's PDF, also known as Version of record

\section{Please check the document version of this publication:}

- A submitted manuscript is the version of the article upon submission and before peer-review. There can be important differences between the submitted version and the official published version of record.

People interested in the research are advised to contact the author for the final version of the publication, or visit the DOI to the publisher's website.

- The final author version and the galley proof are versions of the publication after peer review.

- The final published version features the final layout of the paper including the volume, issue and page numbers.

Link to publication

\footnotetext{
General rights rights.

- You may freely distribute the URL identifying the publication in the public portal. please follow below link for the End User Agreement:

www.umlib.nl/taverne-license

Take down policy

If you believe that this document breaches copyright please contact us at:

repository@maastrichtuniversity.nl

providing details and we will investigate your claim.
}

Copyright and moral rights for the publications made accessible in the public portal are retained by the authors and/or other copyright owners and it is a condition of accessing publications that users recognise and abide by the legal requirements associated with these

- Users may download and print one copy of any publication from the public portal for the purpose of private study or research.

- You may not further distribute the material or use it for any profit-making activity or commercial gain

If the publication is distributed under the terms of Article $25 \mathrm{fa}$ of the Dutch Copyright Act, indicated by the "Taverne" license above, 
VAN VOORPROEVER TOT TOXICOLOOG

PROF. DR. A. BAST 
De wetenschap stalat niet stil. $K$ Bast 


\section{REDE}

\section{UITGESPROKEN BIJ DE AANVAARDING VAN FET AMBT VAN HOOGLERAAR IN DE HUMANE TOXICOLOGIE, AAN DE UNIVERSITETT MAASTRICHT OP VRIJDAG 3 DECEMBER 1999.}

DOOR

PROF, DR A. BAST

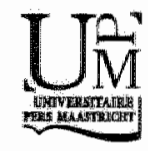





\section{MIJNHEER DE RECTOR MAGNIFICUS, DAMES EN HEREN;}

$\mathrm{Na}$ ruim derrien jaar als moleculair farmacoloog aan de Vrije Universiteir te hebben gewerkt [1], mag ik nu officieel een benoeming als humaan toxicoloog aan de Universiteit Maastricht aanvaarden. Een moleculair farmacoloog aan een Faculteit Scheikunde is geïnteresseerd in de werking van (veelal) lichaamsvreemde stoffen op moleculair niveau, waarbij de gewenste werking van stoffen wordt benadrukt. Je zou kunnen zeggen, dat een moleculair farmacoloog de voorproever is voor de humaan toxicoloog aan een Faculteit Geneeskunde, die is geînteresseerd in het voorkómen van de ongewenste werking van stoffen waaraan een mens wordt blootgesteld. De beweging van voorproever naar toxicoloog, is een beweging van scheikunde naar geneeskunde, van molecuul naar mens en van weten naar kunnen.

Bonaventura Orfilla wordt als grondlegger van de moderne toxicologie gezien [2]. Hij werd geboren in een Spaanse kolonie op een van de eilanden van de Balearen en leefde van 1787-1853. Hij studeerde scheikunde en wiskunde aan de universiteiten van Valencia, Barcelona en Madrid. Met name op grond van zijn kennis van de chemie, wist hij van rijke industriëlen sponsoring te verkrijgen waarmee hij zijn studie kon vervolgen in Parijs. Hij werd arts in 1811. De oorlog maakte terugkeer naar Spanje moeilijk. In $1816 \mathrm{kreeg}$ hij de Franse nationaliteit. Hij bracht het zelfs tot liffarts wan Louis XVIII en werd hoogleraar in de forensische geneeskunde en in de chemie. Tijdens zijn experimenten merkte hij dat verschillende lichaamswloeistoffen anders op toxische stoffen reageerden. Daardoor realiseerde hij zich dat betrouwbare toxicologische informatie niet woorhanden was. Hij 
trok zich terug op het landgoed wan een vriend om dit te onderzoeken. Enige jaren en 4000 opgeofferde honden later, verscheen van zijn hand het eerste deel van wat de basis vormde van de forensische en experimentele toxicologie [3].

De maarschappelijke belangstelling voor toxicologische vragen is groot. Ik geef u enkele voorbeelden.

Zijn er effecten op de gezondheid van de mens door de stoffen die vrijkwamen bij het vliegtuigongeluk, dat plaatsvond in de Bijlmermeer in oktober 1992 ?

Hoe schadelijk waren de Belgische dioxine-kippen?

Had de vervuiling van de blikjes Cola werkelijk een gezondheidseffekt?

Is het zo dat bestrijdingsmiddelen de vruchtbaarheid beïnvloeden?

Zijn de zogenoemde paddo's gevaarlijk?

Toxiciteit of giftigheid is zowel afhankelijk van de dosering of concentratie van de stof waaraan blootstelling plaatsvindt, als van de duur van de blootstelling. Daarmee kan dus iedere stof een toxische werking hebben, zelfs water. In het dagelijks gebruik wan het begrip "toxische stof ", realiseert men zich onvoldoende deze bepalende rol van concentratie en blootstellingsduur. Het begrip toxiciteit heeft voor velen vooral een emotionele lading omdat het in verband wordt gebracht met gevaarlijk en schadelijk. De angst die potentiële blootstelling aan giftige stoffen te weeg brengt vormt een uitstekende mogelijkheid voor de media en voor belangengroeperingen om de aandacht te trekken. Angst is immers nieuws en angstnieuws verkoopt [4].

Angst over een giftige stof, als er geen sprake is van blootstelling aan die stof, is ridicuul. Exploitatie van die angst wordt duidelijk 
bij het zien van de televisiebeelden ten tijde van het dioxineschandaal in België. Een televisiecamera zwenkt langs een stelling in een supermarkt waar katten- en hondenvoer staat opgesteld. Het commentaar stelt met een sonore stem: "Realiseert u zich dat er in dit dierenvoer genoeg dioxine kan zitten om 11 honden te vergiftigen".

De universitair toxicoloog heeft niet alleen een rol als onderwijsgever en onderzoeker maar heeft vanwege de belangstelling die er van uit de maatschappij is, beslist ook een maatschappelijke rol alls gids en voorlichter te vervullen;

\section{GENEESMIDDELEN}

Er is een wisselwerking tussen de toxicologie en de farmacologie. Ervaringskennis van de giftige werking van stoffen was er eerder dan de notie omtrent de gunstige werking van stoffen. De beide disciplines, toxicologie en farmacologie, zoals deze nu worden uitgeoefend, hebben hun basis in de fysiologie. De farmacologie richt zich op geneesmiddelen, stoffen die ingezet worden om een gewenste fysiologische verandering in te zetten. De ongewenste toxiciteit ligt op de loer, zeker bij gebruilk van verschillende geneesmiddelen tegelijkertijd. Minimaal vijf procent van ziekenhuisopnames is het gevolg van verkeerd of van teveel geneesmiddelgebruik $[5,6]$. De humane toxicologie van geneesmiddelen is goed te bestuderen omdat het middel na verschijning op de markt vervolgd wordt en bijwerkingen worden geregistreerd. Veel al is de toxicologie een afgeleide van de gewenste werking" waardoor gerichte pogingen om de toxiciteit te vermijden mogelijk zijn. 
Een mooi voorbeeld is wellicht ons onderzoek dat de bedoeling heeft de toxische bijwerking van bepaalde anti-tumor middelen te voorkomen. In dit onderzoek dat in nauwe samenwerking met Prof. W.J.F. van der Vijgh van de afdeling Medische Oncologie van de Vrije Universiteit wordt uitgevoerd, hebben we ons speciaal gericht op het cytostaticum doxorubicine. Dit geneesmiddel is heel effectief. Het gebruik is echter gelimiteerd tot een maximale dosering $\left(550 \mathrm{mg} / \mathrm{m}^{2}\right)$ doordat er cumularieve dosis afhankelijke toxiciteit in het hart optreedt. Kennis van het mechanisme waarmee de doxorubicine geinduceerde cardiotoxiciteit ontstaat maakte het mogelijk om selectief stoffen te zoeken en te ontwerpen die bescherming bieden tegen deze toxiciteit. Uit de klasse van de flavonoïden wisten we vertegenwoordligers te selecteren die de cardiotoxiciteir van het cytostaticum voorkomen [7]. De selectieprocedure begon met de ontwikkeling van de theorie van het moleculair mechanisme waarlangs de beschermende werking tot stand zou komen. IJzerchelatie en antioxidantwerking moesten volgens onze theorie in de beschermende stoffen zijn verpakt. Vervolgens werden er in vitro, chemische en proefdier afhankelijke experimenten uitgevoerd om uiteindelijk met een beperkte selectie in vivo proefdierexperimenten te komen tot een keuze van een kandidaat stof voor klinisch onderzoek. Het onderzoek illustreert dat we vanuit kennis omtrent het mechanisme van de toxiciteit stapsgewijs in vitro en in vivo onderzoek moeten doorlopen om met succes de klinische fase te kunnen bereiken. Het beschermende flavonoide is eigenlijk een antidotum tegen de door doxorubicine veroorzaakte hartschade. Deze antigifbenadering is klassiek en werd in het verleden al vaak met succes toegepast. Zo werd in 1945 een antidotum tegen verschillende arsenicum bevattende oorlogsgassen bekend, het 'British antiLewisite (BAL)'. Deze stof, het 2,3-dimercaptopropanol, bevat 
twee thiol groepen en beschermt thiol-bevattende enzymen tegen de schadelijke werking van het oorlogsgas [8]. Later bleek dat BAL ook beschermde tegen vergiftigingen met andere zware metalen als cadmium en kwik.

Onderzoek op het terrein wan de toxicologie wan geneesmiddelen is relatief goed uitwoerbaar. Moleculaire mechanistische kennis omtrent de biologische activiteit om je op te baseren is aanwezig, de stof (het geneesmiddel) is voorhanden, de afbraakroutes van het geneesmiddel zijn grotendeels opgehelderd en de metabolieten zijn bekend. Omdat ook over de dosering van de medicatie en de duur van de blootstelling aan geneesmiddelen is nagedacht, kan dit in de overwegingen betrokken worden.

\section{DE VOORPROEVER}

Hoe schrijnend anders is de situatie voor voeding. In zekere zin wisten oude keizers, farao's en koningen dat al. Degenen die bevreesd waren voor een vergiftigingsaanslag via het voedsel namen een voorproever in dienst. Een risicovol beroep, voorproever. Van alles wat de soeverein wilde eten werd wat voorgeproefd. Eigenlijk verschafte de voorproever een schijnzekerheid. Het gif kon immers juist in die ene druif die de machthebber zelf at verstopt zijn. De uitwerking van het gif kon wellicht pas op de lange termijn tot uiting komen. Ook in zo'n geval bracht een voorproever niet de gewenste protectie.

Ook nu, naar aanleiding van enkele recente schandalen, roept de politiek op om voorproevers in te schakelen. De consument heeft recht, zo wordt gesteld, op absoluut veilig voedsel. De controle moet strenger. Men spreekt in dit verband niet alleen over produktveiligheid maar zelfs over integrale ketenbewaking. De we- 
tenschappelijke woorproever van nu, heeft chemisch gereedschap om bepaalde niet gewenste contaminatie wan het woedsel te detecteren. Hij hoeft niet meer zijn eigen leven in te zetten. Maar waar controleren we op, waar zoeken we naar en wat is eigenlijk absolute veiligheid?

De mens is afharkelijk van voeding en wil vanuit die afhankelijkheid geloven dat de voeding veilig is. Dat is een diep geworteld maatschappelijk en individueel gevoel. Als die veiligheid niet gewaarborgd wordt ontstaat een heftige reactie.

De klachten die ontstonden op grond van de vervuilde blikjes Coca Cola in Bellgië konden niet worden teruggevoerd op de contaminatie. De verklaring van de gezondheidsklachten werd elders gezocht. Het drinken van Cola wordt door jongeren gevoeld als een symbool voor vrijheid en onafhankelijkheid. Daarbij kwam dat de melding van de contaminatie van de blikjes, plaats vond in een reeks andere berichtgevingen over vervuiling. Denkt u bijwoorbeeld aan de BSE en de dioxine affaire. Ook andere onzekerheden, bijvoorbeeld rondom her justitiële apparaat, kwamen voortdurend in het nieuws. Met de vervuiling van de blikjes werd ook de laatste door jongeren onaantastbare culturele zekerheid an het wankelen gebracht. $\mathrm{Nu}$ bleek zelfs de Coca Cola niet meer veilig. Op grond van deze overwegingen werd in België verondersteld dat een vorm van massahysterie leidde tot de gezondheidsklachten [9].

Voedselveiligheid is voor de consument zo belangrijk dat allerlei toxicologische mythen worden gebruikt om dit veiligheidsgevoel te staven. Ik geef u enkele voorbeelden:

Ons voedsel bereiden we zelf en is dus veilig.

Gedacht wordt dat we, door zelf ons voedsel te bereiden, weten wat we eten. Dat is echter geenszins het geval. Tijdens de berei- 
ding van ons voedsel ontstaan vele nieuwe reactieproducten. Vetten oxideren, eiwitten vallen uiteen, brokstukken van eiwitten reageren met vetoxidatieproducten, vitaminen oxideren tot nieuwe producten, enz. Van de meeste van die nieuwe reactieproducten weten we niets t.a.v. de effecten op de gezondheid. De expositieduur is overigens lang, een leven lang.

Voeding is wan oudsher bekend en moet dus wel veilig zijn.

Ook dit is een argument zonder grond. Vele gewassen zijn immers pas gedurende de laatste paar eeuwen gecultiveerd. Nieuwe onbekende gewassen en vruchten uit andere streken bereiken ons. Producten waar we nog nooit aan zijn blootgesteld. De meeste inhoudsstoffen, laat staan de gezondheidseffecten van die stoffen, van onze voeding kennen we niet.

\section{Voeding is natuurlijk en dus veilig.}

In deze mythe is natuurlijk een synoniem voor veilig. In deze denktrant staat chemisch voor gevaarlijk. Het geloof in deze mythe gaat zelfs zover dat biologische landbouw, landbouw zonder gebruik van bestrijdingsmiddelen, een uitgebreide subsidiëring kent. Men realiseert zich onvoldoende dat de biologische landbouw bij voorkeur gewassen gebruikt, die een hoge natuurlijke resistentie tegen ziekten hebben. Een van de manieren om de resistentie te verkrijgen is her gebruik van gewassen met relatief veel natuurlijke toxinen. Stoffen met een insecticide werking zijn van nature vol op aanwezig in planten [10]. Planten beschikken op deze manier over een natuurlijke defensie tegen vraat. Een evolutionair voordeel, want planten kunnen immers niet weglopen indien ze worden aangevallen. Veel van deze natuurlijke toxines hebben ook een vervelende werking op de mens. 
Andere argumenten tegen biologische landbouw zijn de veel lagere opbrengsten (ongeveer $30 \%$ lager) in vergelijking met de opbrengsten zoals die nu behaald worden in de reguliere landbouw [11]. Er is dus meer landbouwgrond bij biologische teelt nodig om an dezelfde opbrengst te komen. Zonder bestrijdingsmiddelen is de kans op schadelijk onkruid groter. Een voorbeeld hiervan zijn de bessen van de nachtschade in de erwten. De consument houdt echter halsstarrig vast aan de mythe dat de natuur veiligheid biedt en de politiek volgt die mening. Een goede afwreging van humaan toxicologische en ecotoxicologische voor- en nadelen ontbreekt. De stemmen van de wetenschappelijke voorproevers horen we overigens nauwelijks.

\section{ZUURSTOF}

Het is voorzichtig gezegd, merkwaardig, dat de maatschappelijk geaccepteerde en favoriete fobieèn vaak irrationeel en overdreven zijn [12] en dat de risico's die er echt toe doen, niet voldoende gewogen worden. Zuurstof is een voorbeeld van een risicovolle potentieel schadelijke stof. In het algemeen wordt dat overigens anders ervaren en wordt zuurstof gezien als een levenselixer, waar je niet genoeg van binnen kunt krijgen. In de zomer van 1999 staat op de voorpagina van een landelijk dagblad [13] dat een groot concern wan plan is om zuurstofbars te introduceren. In die bars kan men, lui en onderuit gezakt in een gemakkelijke stoel met een rustgevend muziekje, $100 \%$ zuurstof inademen. $\mathrm{Er}$ wordt door een woordvoerder van het concern gesteld dat er door de milieuvervuiling en huilige stress behoefte is aan deze zuurstofinademing. Het beloofde resultaat is dat, na een kwartier snuiven, een verkwikt en energiek gevoel ontstaat. In dit geval 
was het eenvoudig om de onzin te ontmaskeren [13]. Het gaat echter verder. We weten dat zuurstof al bij $21 \%$ mogelijk schadelijke effecten teweeg kan brengen. Dat komt doordat zuurstof cenvoudig, tijdens allerlei processen in ons lichaam, wordt omgezet in verschillende reactieve vormen van zuurstof. Deze reactieve zuurstofvormen worden benut in de fysiologie, bijvoorbeeld bij het opruimen van microbièle binnendringers, bij de afbraak van lichaamswreemde stoffen of bij de regulatie van de bloeddruk. Tegelijkertijd geven deze reactieve zuurstofvormen schade aan het weefsel als er te veel van gevormd wordt. De fysiologie kan gebruik maken van deze reactieve zuurstofvormen doordat zogenoemde antioxidanten de reactiviteit en daarmee de schade beteugelen. Zuurstof wordt wel gezien als de paradox van aërobe levensvormen: men kan niet zonder zuurstof, maar uiteindelijk krijgt de zuurstoftoxiciteit toch de overhand. De duur van de blootsrelling mag er dan ook zijn: levenslang. Verschillende chronische ouderdomsziekten zijn geassocieerd met deze toxiciteit van zuurstof. Twee belangrijke voorbeelden zijn: Type 2 of ouderdomsdiabetes [14] en verschillende longziekten waaronder COPD [15]. Langdurige blootstelling aan hoge zuurstofspanningen kan schade veroorzaken. In de neonatologie is de zuurstoftoxiciteit een bekend fenomeen. De pasgeboren baby kan door een te hoge zuurstofspanning longschade (bronchopulmonale dysplasie) of oogschade (retinopathie) oplopen.

Kortom, verstandig van het concern om daags na de nationale aankondiging van de verkwikkende zuurstofbar, toch te besluiten dit niet te introduceren. Zuurstof is immers een giftige stof, omdat reactieve afbraakproducten van zuurstof in het lichaam kunnen ontstaan en de blootstelling aan de stof continu plaats vindt. Het is dan ook goed voor te stellen dat momenteel de aandacht in de toxicologie voor de schadelijke werking van zuurstof groot 
is [16]. De reactiviteit van zuurstofmetabolieten geeft niet alleen schade, maar heeft ook een belangrijke fysiologische rol. Daarom is her ontwerp van een adequaat antidotum tegen reactieve zuurstofmetabolieten geen sinecure (vide infra).

\section{ANTIOXIDANTEN ALS NUTRICEUTICA?}

Voeding vormt een belangrijke bron voor stoffen die de zuurstofschade kunnen voorkomen, de zogenoemde antioxidanten. Een antioxidant voorkomt of vertragt de oxidatie van een andere stof. Daarmee is al iets van de magie van antioxidanten weggenomen. Indien immers twee stoffen worden vergeleken en stof $A$ sneller oxideert dan stof $B$, dan heeft in dit systeem stof $A$ antioxidant eigenschappen. Ontdekking van nieuwe antioxidanten in de voeding heeft dan ook niet lets verrassends. De antioxidanten in de voeding walar veel aandacht voor is, zijn de vetoplosbare vitamine $\mathrm{E}$ en carotenoïden en het wateroplosbare vitamine $\mathrm{C}$. Deze klassen van antioxidanten hebben een verschillende locatie in de cel en een verschillend werkingsmechanisme $[17,18]$. Ook zijn er diverse enzymen in ons lichaam aanwezig die bescherming bieden tegen reactieve zuurstofvormen. De niet-enzymatische en enzymatische beschermingssystemen vormen een ingewilkkeld netwerk waarmee de door zuurstof veroorzaakte cellulaire schade wordt beperkt. Deze stoffen staan dan ook sterk in de belangstelling. Interessante vragen komen op. Kunnen we de antioxidant met een gezondheidsbevorderend effect verpakken in een voedingsmiddel en daarmee functionele voeding creèren die op de werking van antioxidanten is gebaseerd? Of kunnen we de antioxidant in een farmaceutische vorm toedienen en er een nutriceuticum, een voedingsstof die werkt als een geneesmiddel, van 
maken? De mogelijkheden prikkelen de fantasie. Zouden we op deze manier de zuurstoftoxiciteit kunnen voorkomen? Nieuwe medische voedingstherapieën zijn er reeds op gebaseerd: Veel van deze therapieèn stoelen echter op meningen en niet op feiten, op geloof en niet op onderzoeksgegevens. Feiten zijn dat:

Het onderzoek naar de werking van functionele voeding en nutriceutica nog in de kindersehoenen staat.

Van ieder geneesmiddel is het afbraakprofiel (het metabolisme) bekend. Van antioxidanten zijn de afbraakroutes nauwelijks bekend. Dat is merkwaardig omdat een metaboliet al ontstaat als de antioxidant heeft gewerkt. De stof wordt dan immers geoxideerd.

De activiteiten van de metabolieten van antioxidanten nawwelijks bekend zign.

Met vitamine $\mathrm{E}$ bijvoorbeeld, geven we een serie stoffen aan. Dat deze vitameren andere metabolieten geven en onderscheidende activiteiten hebben, begint zich langzaam af te tekenen.

De kinetiek, de opname en de optimale dosering voor antioxidanten nawwelijks of niet bekend zijn.

De samenstelling van het antioxidantnetwerk verschilt tussen de verschillende organen. Suppletie met antioxidanten kan wellicht voor diverse organen en de verschillende celllulaire compartimenten anders uitwerken.

Veiligheidsonderzoek ontbreekt.

Chronische toepassing van deze stoffen vereist een afweging tussen risico en nut van 
Adequate en gerichte suppletie niet mogelijk is omdat bij de verschillende zuurstof-gemedieerde ziekten niet bekend is boe bet antiosidantnetwerk verandert bet gebruik.

Meningen over het gebruik van antioxidanten als antidotum tegen zuurstoftoxiciteit zijn er vol op. Voorbeelden van meningen, die niet stoelen op feiten zijn:

Antioxidanten moeten hoog gedoseerd kunnen worden om een optimale voeding te bereiken.

Hierbiij worden doseringen doseringen van 20 maal (of hoger) de aanbevolen dagelijkse hoeveelheid $(\mathrm{ADH})$ niet geschuwd. Hierbij is optimaal niet goed te definiëren. Tevens moet worden bedacht dat de $\mathrm{ADH}$ vroeger is ingesteld omdat het soms moeilijk bleek om genoeg van de vitaminen en mineralen via de voeding op te nemen. Nu lijkt de situatie eerder zo te zijn dat voorzichtigheid betracht moet worden ten einde niet over de veilig geachte dosis heen te schieten.

De natuurlijke antioxidanten bebben geen bijwerkingen, bet zijn immers natuurlijke stoffen.

Antioxidanten zijn werkzame verbindingen en moeten als zodanig worden beschouwd

Antioxidanten zijn geen geneesmiddelen, ze worden immers bij woorkeur ter preventie wan ziekte ingezet.

Dit ontslaat degene die de middelen op de markt brengt nog niet van weiligheidsonderzoek. Men vergeet hierbij trouwens dat verschillende geneesmiddelen ook preventief worden gebruikt. Te derken valt hierbij aan middelen tegen hoge bloeddruk of tegen een te hoog cholesterol gehalte in het bloed. Overigens is het zeer 
goed denkbaar dat in de toekomst, antioxidanten wel als geneesmiddel worden ingezer. Er zijn al interesssante voorbeelden.

We voegen antioxidanten toe aan de shampoo, can cosmetica (in dat verband spreekt men zelfs wel van cosmeceutica), an de tandpasta en aan snoepgoed. In alle gevallen beeft dit een gunstig effect.

Een merkwaardige en ongegronde vitaminerage. Vitaminen staan voor velen synoniem met gezond. Onterecht want ook voor vitaminen gaat de beroemde uitspraak van Paracelsus (1493-1541) op: "Wenn ihr jedes Gifft recht wolt auslegen / was ist das nit Gifft ist? alle ding sind Gifft / und nichts ohn Gifft / allein die Dosis macht / das ein ding kein Gifft ist".

Een dergelijke opsomming levert een weelheid aan onderzoeksvragen op. Ik hoop een bijdrage aan dit onderzoek te kunnen leveren. Het verschil tussen een geneesmiddel en voeding is een glijdende schaal. Aan de ene kant van de schaal ligt het geneesmiddel met een duidelijke medische claim dat op recept verkrijgbaar is, daarnaast ligt de OTC (Over The Counter) het geneesmiddel zonder recept en de voedingscomponent met een licht medische claim, daarnaast de voedingscomponent met een gezondheidsclaim en tenslotte aan de andere kant van de schaal vinden we voeding zonder gezondheidsclaim. Het lijkt mij dat hoe stelliger de claim is, hoe steviger het onderzoeksdossier t.a.v. de bewijsvoering over die claims moet zijn. Veiligheid van gebruik blijft buiten kijf en uiterst relevant in alle gevallen. Nadere regelgeving op dit gebied is wan node. 
De fysiologie van ieder individu is verschillend. Extreme fenotypische verschillen zoals die tussen zieke en gezonde personen, zijn heel wel te duiden. Behandeling is er op gericht om de fysiologische aberraties weer binnen de gewenste normale grenzen te krijgen.

Meer en meer wordt duidelijk dat ook genetische verschillen tussen personen een rol spelen in de individuele gevoeligheid voor ziekten. Een interessant voorbeeld in dit verband is het enzym glucose-6-fosfaat dehydrogenase. Dit enzym zorgt voor het instant houden van de antioxidantniveaus. In het bijzonder bij mensen rondom de Middellandse Zee komt een genetisch defect in dit enzym voor. Het eten van bepaalde bonen die een aanspraak doen op de antioxidanten, kan bij deze mensen leiden tor

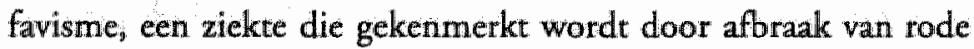
bloedcellen, hoge koorts, leverbeschadiging en vergroting van de milt. Ook de gevoeligheid voor longschade door geneesmiddelen kan toenemen, zoals recent hier in Maastricht op de afdeling Pulmonologie is vastgesteld [19]. Er zijn al meer voorbeelden waarin de enzymactiviteit gekoppeld wordt aan het risico dat iemand loopt op het krijgen van een longziekte [bijv. 20]. Op deze manier is het mogelijk om groepen te identificeren die een verhoogd risico op een bepaalde ziekte lopen. Een gericht voedingsadvies met een minimaal risico ligt dan in de rede. Deze trend heeft zich ingezet en dit gebied, de toxicogenetica, zal een rol gaan spelen in de beroepsinvulling van de toxicoloog. De rol van de toxicoloog als verbieder, de verbodstoxicoloog die aangeeft wat giftig is en vermeden dient te worden, zal vervagen. De rol van de toxicoloog die zich bezig houdt met risicomanagement 
zal zich verder versterken. In deze rol kan de toxicoloog individuen, die gevoelig zijn voor bepaalde risico's, karakteriseren.

In dit risicomanagement is nauwelijks plaats voor het voorzorgsprincipe, zoals dat door de milieubeweging graag wordt gebezigd. Het voorzorgsprincipe stelt dat indien je de risico's van iets niet precies weet, je dit achterwege moet laten. Het is verlejdelijk om bij gebrek aan toxicologische normen terug te grijpen naar het voorzorgsprincipe. Het voorzorgs- of "better safe then sorry" principe werkt echter verlammend op nieuwe ontwikkelingen en leidt tot verkeerde inzet van beschikbare financiën. Het voorzorgsprincipe is eigenlijk een nalatigheidsprincipe. Goede risicomanagement strategieën geven de ruimte om, indien nodig normen bij te kunnen stellen, voordat zinloze draconische geldverslindende maatregelen worden doorgevoerd.

Een van de grote moeilijkheden in de toxicologie was het vinden van goede biomerkers. Indicatoren, die iets zeggen over de processen die zich afspelen in de fysiologie. Ook hier doen zich nieuwe mogelijkheden voor. De toxicogenetica zal immers opgevolgd worden door de toxicoproteomica. Eiwitprofielen die veranderen als gevolg van expositie. Zelf hebben we in samenwerking met Dr. H. van den Berg van TNO-Voeding, inmiddels enige ervaring opgedaan met transcriptiefactoren als biomerker voor oxidatieve schade.

Ook vindt er een maatschappelijke individualisering plaats. Overheid en technologie vormen niet langer de belangrijkste sturende factoren in de het gedrag van de consument. Media, consumentenorganisaties, industrieën en grote winkelbedrijven lijken veel bepalender voor consumentengedrag. Grote industrieên bespeuren dit ook en houden zich meer en meer met ethische vragen bezig. Deze tendens llegt ook een belangrijke verantwoordelijkheid bij de wetenschap. Belangengroeperingen dienen met 
enig wantrouwen en kritisch bekeken te worden. Oneerlijke en ongenuanceerde informatie moet door de wetenschapper aan de kaak worden gesteld.

\section{RISICOPERCEPTIE}

Tenslotte keer ik nog even terug naar de voorproever van vroeger. De voor ons bekendste voorproevers zijn wel de schenker en de bakker die figureerden in het werhaal 'De dromen van schenker en bakker" in Genesis 40. Voorproevers in het oude Egypte behoorden tot de hoge adel. Niet iedereen mocht zomaar de Farao het eten aanreiken. Eten werd ervaren als een religieuze aangelegenhieid. De bereiding ervan kon, zeker indien dat voor de Farao was bedoeld, niet zomaar aan iedereen worden overgelaten. Voedingsmiddelen werden gezien als dragers van het leven [21]. De extreme aandacht van dit moment voor de gezondheidsbevorderende effecten van functionele voeding en nutriceutica, ligt erg dicht bij die oude gedachten over de levensdragende kracht die van voedsel uitging. Trouwens, met het oog op de vergelijking tussen voorproever en toxicoloog, vind ik de beschrijving van een voorproever als iemand die een bijzonder belangrijke functie bekleedde ook wel aantrekkelijk.

De consument van nu heeft een geheel andere risicoperceptie dan de Farao van toen:

Er is cen ruimere voedselkeuze nu. In de westerse wereld is er voldoende voedsel. Men heeft hier de luxe om zich meer te kunnen richten op de gezondheidsaspecten van het voedsel. De markt voor functionele voeding of verrijkte voeding is volop in beweging. Bewijswoering van de gunstige effecten van deze voeding wordt nauwelijks gevraagd. Over veiligheidsstudies in relatie tot 
het nut van deze voeding wordt al helemaal niet gerept. De consument vraagt, de fabrikant levert. Goede industrieèn zullen zich kenmerken door wel de juiste bewijsvoering te leveren om de gezondheidsclaims te motiveren. Deze betrouwbare industrieèn zullen ook een risico versus gezondheidswinst (risk-benefit) analyse uit te voeren. De academische wereld dient daar ook op aan te dringen en misstanden te signaleren.

Als er iets mis is met $10 \mathrm{~kg}$ voedsel is dat direct mieuws. De aandacht voor een klein ongeluk met enkele kilogrammen voedsel is merkwaardig, als dit wordt afgezet tegen het gegeven dat tegelijkertijd miljoenen kilogrammen voedsel geproduceerd worden. Een kleinigheidje is direct nieuws.

De snelle communicatie versnelt en versterkt het nieuws. De krantenkoppen schreeuwen het ongelukje nog dezelfde dag. Als reactie zien we dat het wantrouwen over voedselveiligheid toeneemt. Daardoor wordt het risico uitvergroot en irreëel. In de westerse wereld hebben wij die luxe. Het echte risico ligt echter in een voedseltekort en reële deficiënties in de derde wereld.

$\mathrm{U}$ merkt er is veel te doen. Er zijn meer maatschappelijk geëngageerde toxicologen nodig die niet schromen om met wetenschappelijke argumenten de reële risico's te scheiden van spookverhalen. 

Met het uitspreken van deze rede heb ik vandaag een boeiende leeropdracht aanvaard. Het vakgebied van de Humane Toxicologie zoals naar ik hoop door ons bewerkt zal worden staat midden in de wetenschappelijke belangstelling. In 2010 is één op de drie mensen ouder dan 50 jaar. Bestrijding van oxidant-gemedieerde ouderdomsziekten zal van toenemend belang worden. Antioxidanten als beschermende stoffen zijn veelbelovend in dit opzicht. Voeding lijkt in dit geval een uitstekend medium om de chronische toxiciteit van zuurstof te voorkomen. Dagelijks spelen er onderwerpen van de antropocentrische toxicologie in het maatschappelijk debat. Ik hoop dat ons onderzoek en onze maatschappelijke betrokkenheid voor de studenten een stimulans vormt om zich in dit vakgebied te verdiepen.

Graag wil ik het College van Bestuur van de Universiteir Maastricht en het Faculteitsbestuur Geneeskunde bedanken voor het in mij gestelde vertrouwen.

Leden van de Capaciteitsgroep Farmacologie en Toxicologie, u will ik bedanken voor de open wijze waarop u de nieuwe spelers op het gebied van de Humane Toxicologie in uw midden heeft opgenomen. Onderzoek doe je met anderen. Ik prijs me gelukkig creatieve sparringpartners in het onderzoek te hebben. Ik hoop dat er van deze interne wetenschappelijke discussies een bezieling uit gaat die ook voor promovendi en studenten stimulerend werkt.

Ik heb reeds gemerkt dat er vanuit de kliniek interesse is voor ons onderzoeksgebied. I hoop dat wij met $\mathrm{u}$ kunnen nagaan of de kennis die wij als moleculaire voorproever hebben opgedaan een klinische relevantie heeft. 
In mijn academische omzwervingen in Faculteiten Scheikunde (Vrije Universiteit), Geneeskunde (Erasmus Universiteit) en Farmacie (Universiteit Utrechr) heb ik verschillende leermeesters en collegae gehad. Een ieder bracht eigen accenten in en vormde de onderzoeker die ik nu ben. Velen hebben bijgedragen aan mijn vorming en aan de onderzoeksresultaten die tot dus ver zijn behaaid. Het is nog immer een groot plezier om in een academische setting in vrijheid en tegelijkertijd in samenspraak met anderen onderzoek te kunnen doen.

Mijn moeder wil ik bedanken voor haar stimulerende rol in mijn leven. Het motto van deze rede is "de wetenschap staat niet stil", een uiltspraak die mijn vader vroeger deed.

Mijn echtgenote Wendelien en mijn dochters Bertine en Klaske vormen het warme thuisfront. Samen kunnen we de wereld aan.

Ik heb gezegd. 


\section{NOTEN}

[1] BAST A. Voedsel, vergift en geneesmiddel. Radicaal gelijk. Oratie, VU Amsterdam 22 maart 1990.

[2] HOLMSTEDT B and G LLIJESTRAND. Readings in pharmacology. Raven Press, New York, 1981.

[3] ORFILA MJB. Traité des poisons tirếs des règnes minéral, végétal et animal ou roxicologie général considerée sous les rapports de la pathologie et de la médecine legale. Crochard, Paris, 1814.

[4] WHELAN EM. Toxic terror. The truth behind the cancer scares. Prometheus Books, New York, 1993.

[5] FRADET G, X LEGAC, T CHARLOIS, T PONGE and S COTIIN. Iatrogenic drug-induced diseases, requiring hospitalization, in patients over 65 years of age. One year retrospective study in an internal medicine department. Rev. Med. Interne 17, 456-460 (1996).

[6] TAMBLYN R Medication use in seniors: challenges and solutions. Therapie $51,269-282(1996)$

[7] VAN ACKER SABE, K KRAMER, JA GRIMBERGEN, D.J VAN DEN BERG, WJF VAN DER VIJGH and A BAST. Monohydroxyerhylrutoside as protector against chronic doxorubicin-induced cardiotoxicity. Br. J. Pharmacol. $115,1260-1264$ (1995).

[8] PETERS RA, LA STOCKEN and RHS THOMPSON. British antiLewisite (BAL). Nature (Lond.) 156, 616-619, 1945.

9] NEMERY B, B FISCHLER, M BOOGAERTS, D LISONS. Dioxins, Coca-Cola, and mass sociogenic illness in Belgium. Lancet 354, 77 (1999). Een persoonlijke mededeling van Prof. Dr. B. Nemery, toxicoloog te Leuven. 
[10] DMELLO JPF, CM DUFFUS, JH DUFFUS. Toxic substances in crop plants. The Royal Society of Chemistry, Cambridge, 1991.

[11] JANSSEN PAH and JC HANEKAMP. Gewasbescherming: een toxicologisch perspectief. Stichting, HAN, Amsterdam, 1999.

[112] BATE R. What risk? Science, politics and public health. Butterworth Heinemann, Oxford. 1999.

113: Bijtanken in de zuurstofbar, Algemeen Dagblad 5 augustus 1999. Bijenkorf schrapt de zuurstofbar - Gezondheidsrisicico's nier te overzien, Algemeen Dagblad 6 augustus 1999.

[14] BIEWENGA GP, GRMM HAENEN and A BAST. The role of lipoic acid in the treatment of diabetic polyneuroparhy. Drug Metab. Rew. 29, 1025 1054 (1998).

[15] REPINE JE, A BAST and ILM LANKHORST (on behalf of the international oxidative stress study dub). Oxidative stress in COPD. Am. J. Resp. Crit. Care Med.156, 341-358 (1997).

[16] Het eerste deel van het dit jaar verschenen Current protocols in toxicology (Ed. MD Maines), John Wiley and Sons, New York, is voor een groot deel gewijd aan zuurstoftoxiciteit en beschermende systemen tegen deze roxiciteit.

[17] VAN ACKER SABE, LHM KOYMANS and A BAST. Molecular pharmacology of vitamin E. Free Rad. Biol. Med. 15, 311-328 (1993).

[18] BAST A, GRMM HAENEN, R VAN DEN BERG and H VAN DEN BERG. Antioxidant effects of carotenoids. Int. J. Vit. Nutr. Res. 68, 399-403 (1998).

[19] DRENT M. Drug-irduced preurnonia associated with hemizygote glucose-6-phosphate dehydrogenase deficiency. Eur. J. Haemarol. 61, 218-220 (1998). 
[20] SMTH CA, D) HARRISON. Association between polymorphism in gene for microsomal epoxide laydwolase and susceptibility to emphysema. Lancet $350,630-633(1997)$

[21] Met dank aan Dr. J.C. Hanelamp senior en Dr. J.C. Hanekamp junitor voor de informatie over de achtergronden van het verhal in Genesis 40:1-23. 
Want bij herstelde de overste der schenkers in zijn schenkersambt, zodat bij de beker weer in Farao's hand gaf. Maar de overste der bakkers hing hij op, zoals Jozef bun had uitgelegd.

Genesis 40: $21-22$ 

(C) A. Bast, Maastricht 1999

ISBN: 9052782717

Universitaire Pers Maastricht

Vormgeving en druk: Datawyse 